\title{
Study of Switching Transients on EHV AC Transmission Line
}

\author{
Sudhir Kumar Singh \\ Department of Electrical Engineering, IMS Engineering, College Ghaziabad (UP) India
}

\begin{abstract}
Discussion is presented of the results obtained from MATLAB simulation of $735 \mathrm{KV}$ transmission line which was conducted to find out switching surge transients. The Aim of this paper is to study different switching over voltages and find out worst case among all which is helpful for economic insulation design of power system.
\end{abstract}

Keywords: Circuit Breaker (C.B), closing, reclosing, energization, deenergization, compensation

\section{Introduction}

Trapped charges during switching operation of line (generally reclosing) cause severe damage to insulation of equipments used in power system. Energizing and reenergizing of line generates switching overvoltages which in some circumstance be more severe than lighting damage. Now days, increasing load and requirements, Transmission voltages are on increase and also line length and generating station capacity all increased which makes study of switching overvoltages more important. As this is important to note down that in EHV and UHV Transmission system switching overvoltages are more severe than lightning overvoltages so economic insulation cost in these system are feasible only considering switching transients. Over currents are generated by Short circuit and lightning but this is not scope of study in this discussion. Some overvoltages are generated by interruption of short circuit current in form of restriking and recovery voltages also when $\mathrm{CB}$ interrupts fault current at infinite bus terminal whose inductance is quite low to neglect cause overvoltages and this phenomenon is called current chopping. Interruption of small capacitive currents brings overvoltages. However most severe over voltage obtained when CB energizes long EHV transmission line. The line may carry trap charge or it could be reclose with trapped charges. Trapped charges are nothing but electromagnetic and electrostatic energies in long line due to inherent inductance and capacitance of line. Switching overvoltages governed insulation design of EHV/UHV transmission line.

\section{Scope of Study}

1) To know maximum switching surge magnitude for low and high side switching.

2) To know maximum rate of rise of surge on transmission line

3) To know effect of series compensation, transformer tertiaries, transformer impedance, line length on switching surge magnitude and shape.

4) To know the effect of lightning arresters.

5) To know the effect of pre insertion resistance in closing and opening of circuit breaker.

6) To know the effect of deenergization of line due to fault.

\section{System Representation}

A three-phase, $50 \mathrm{~Hz}, 735 \mathrm{kV}$ power system transmitting power from a power plant consisting of six 350 MVA generators to an equivalent network through a $300 \mathrm{~km}$ transmission line. This is modulated on Matlab simulink model.Simulink is a software tool for simulating, modelling and analysing systems. It supports linear as well as nonlinear systems, modelled in continuous time, sampled time or hybrid of both. Study of switching over voltages is done considering open circuited line at receiving end. This is the important case from standpoint of designing insulation required in line since it gives worst or highest magnitude of over voltages under switching conditions. High side and low side switching both are considered. High side means C.B are taken on high voltage side of transformer and likewise low side switching. In our analysis we are merely interested in highest peak amongst the all three phases. So in all figures shown below we have taken all phases in one single axis using SCOPE in MATLAB.

\section{High side switching:}

1) Energization without trapped charge :

Circuit Breaker open initially and closed at second cycle it means at $50 \mathrm{~Hz}$ frequency this is equal to $40 \mathrm{milli}$ second and after this it is observed that at open end of line $2.40 \mathrm{pu} \mathrm{L}-\mathrm{N}$ voltage appear which is shown in Fig 1.

2) Energization of line with trapped charge:

This is called reclosing operation and transient associated with this is called reclosing transient. This is simulated in MATLAB and C.B was open initially and closed in $10^{\text {th }}$ cycle, open in $30^{\text {th }}$ cycle and again close in $35^{\text {th }}$ cycle means it is sudden reclosing. After this analysis we came to the conclusion with two following observations.

Observation 2a: Reclosing transients contains peak of 3.17 pu L-N voltage shown in fig. $2 \mathrm{a}$ it means Reclosing transients are more severe than closing transients. In this figure it is also observed that there is Trapped charges of approximately $+1,+1,-1$ appear in all the three phases 


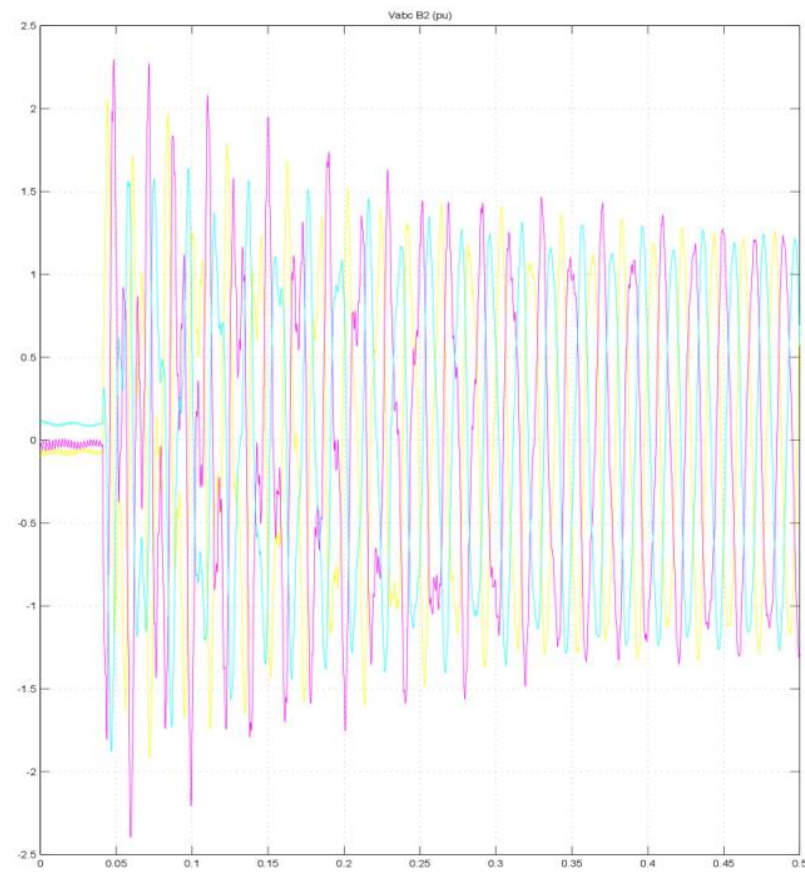

Figure 1: (0.5 pu/div vertical axis, $0.05 \mathrm{sec} / \mathrm{div}$ horizontal axis)

Observation 2b: Reclosing transients take 2.5 milli seconds to reach the peak shown in fig $2 b$

\section{1) Deenergization without fault}

This case is shown in Fig 3 no fault is taken in line and C.B opened suddenly, we observed that Trapped charges are decreasing with time with two phases having same polarity and one having opposite polarity. The reason for decrease in Trapped charges are due to mainly Transformer which drains these charges in few cycles

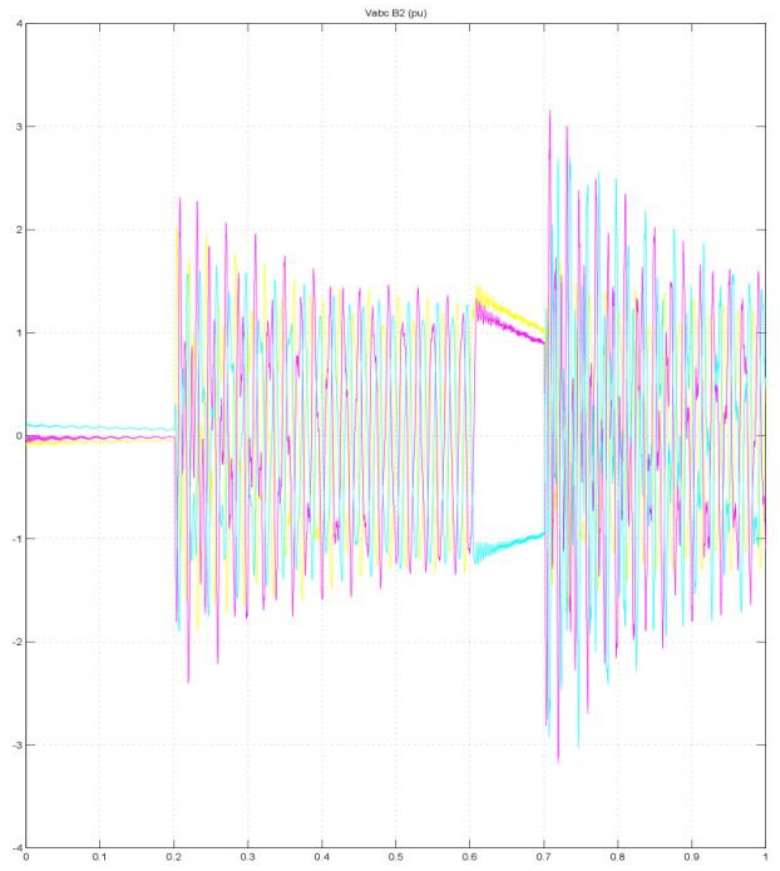

Figure 2a: (1 pu/div vertical axis, $0.1 \mathrm{sec} / \mathrm{div}$ horizontal axis)

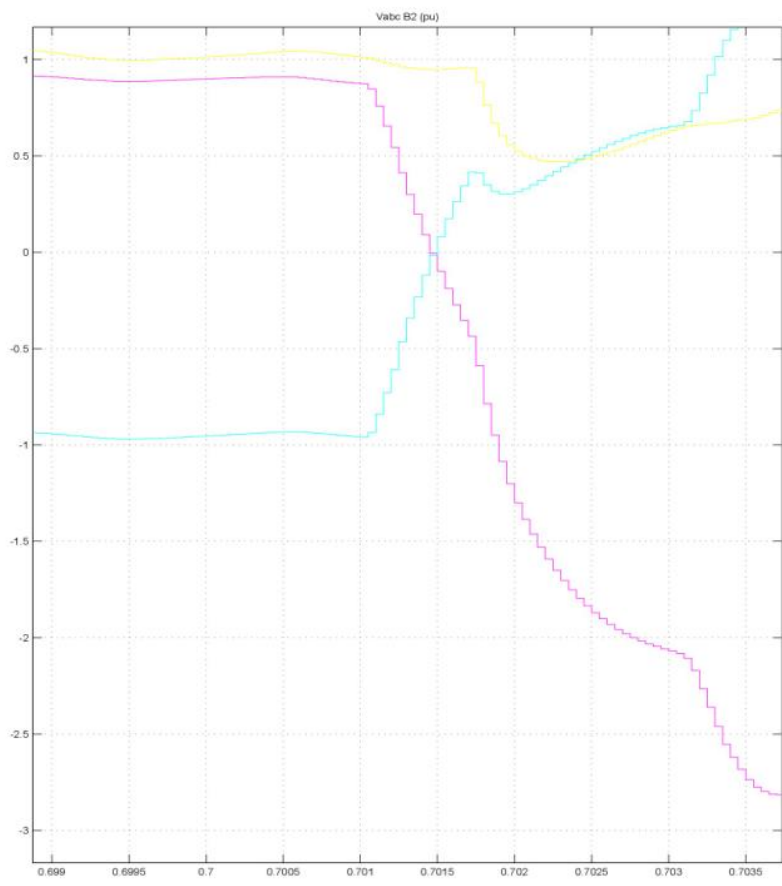

Figure 2b: $(0.5 \mathrm{pu} / \mathrm{div}$ vertical axis, $0.005 \mathrm{sec} / \mathrm{div}$ horizontal axis)

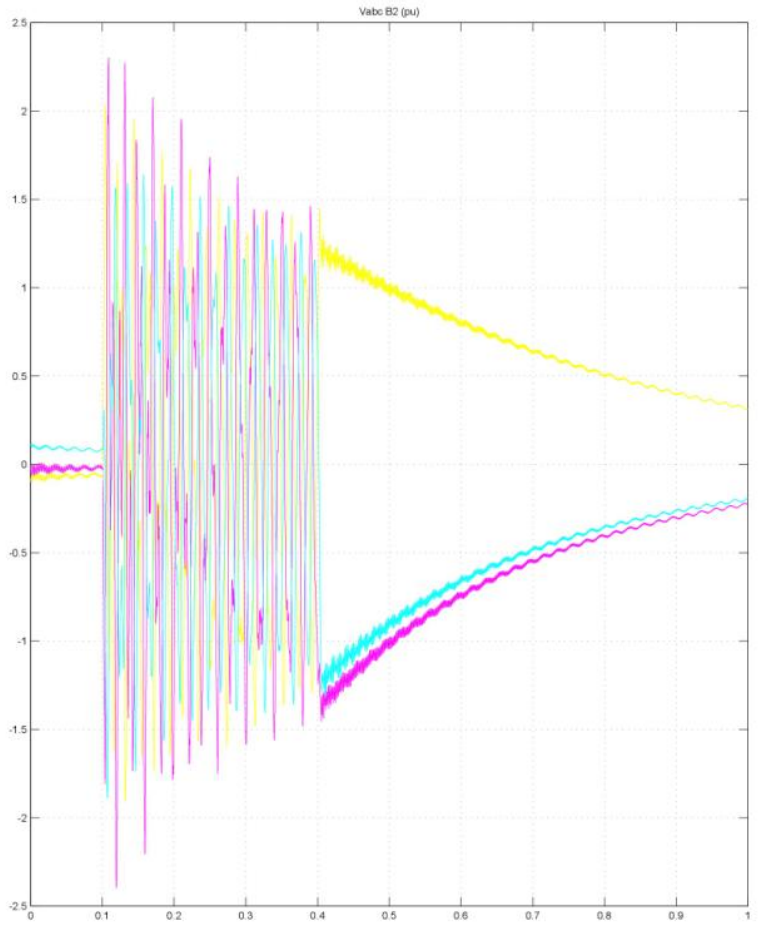

Figure 3: (0.5 pu/div vertical axis, $0.1 \mathrm{sec} / \mathrm{div}$ horizontal axis)

\section{2) De energization with LG fault}

Line to ground fault (LG) is simulated in Matlab.

LG occurs in phase A

C.B open initially

Closed at $1 / 50\left(\right.$ means $1^{\text {st }}$ cycle $)=0.02 \mathrm{sec}$

LG fault at $5 / 50=0.1 \sec \left(\mathrm{V}_{\mathrm{a}}=0\right)$ overvoltage in sound phase are $2.35 \mathrm{pu}$

C.B open at $10 / 50=0.2 \mathrm{sec}$ overvoltage of $1.25 \mathrm{pu}$

Fault cleared at $12 / 50=0.24 \mathrm{sec}$ it is shown in Fig 4 


\section{International Journal of Science and Research (IJSR) \\ ISSN (Online): 2319-7064}

Index Copernicus Value (2013): 6.14 | Impact Factor (2015): 6.391

\section{Low side switching:}

1. C.B open initially and then closed. it is observed that L-N voltage of $2.3 \mathrm{pu}$ approx. found at open ended thus low side switching without transformer tertiary produce approximately same pu voltage as at high side energization without trapped charge because in low side C.B switch both transformer and transmission line since transformer drains stored charges upto 8-10 cycles thus this is case of untrapped charge closing shown in fig 5 .

2. Energization of transformer terminated line: In this case high side switching of C.B is simulated and transformer with no tertiary is used near

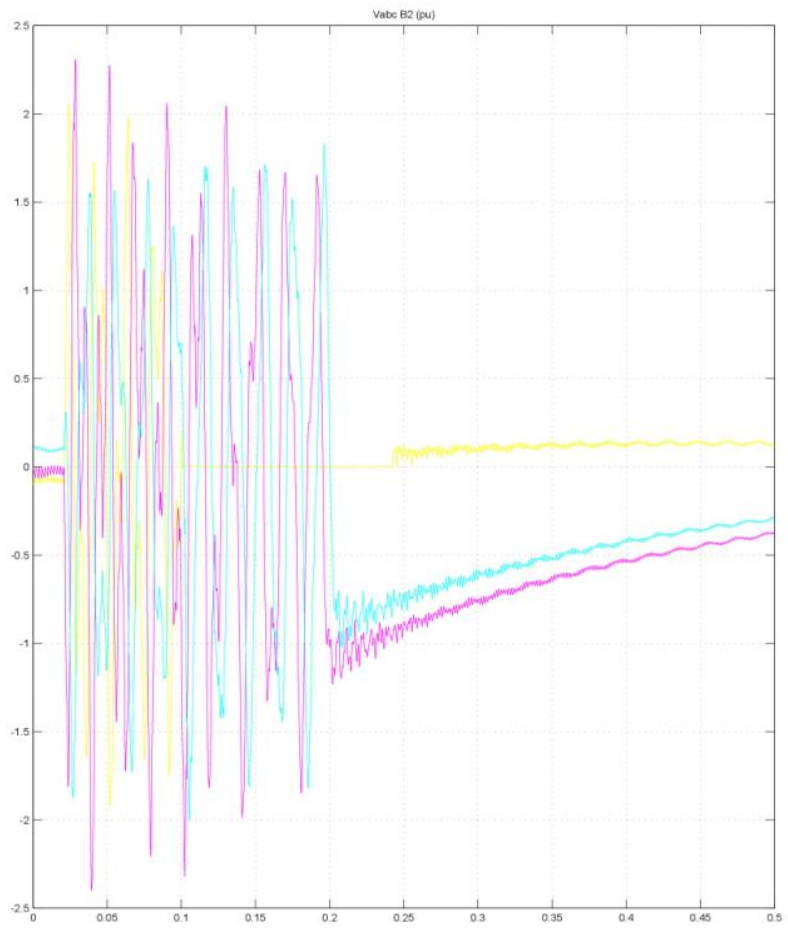

Figure 4: (0.5 pu/div vertical axis, $0.05 \mathrm{sec} / \mathrm{div}$ horizontal axis)

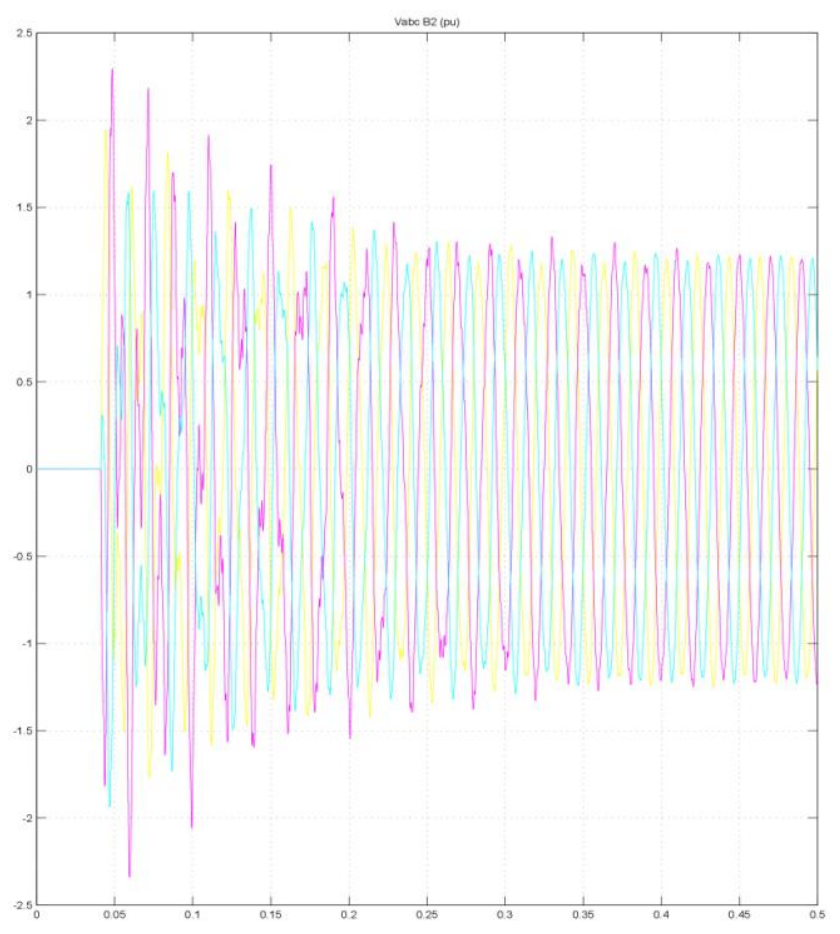

Figure 5: $(0.5 \mathrm{pu} / \mathrm{div}$ vertical axis, $0.05 \mathrm{sec} / \mathrm{div}$ horizontal axis)

\section{Effect of Source Transformer Tertiary Effect}

1) High side switching : switching with trapped charge of open ended line with tertiary 2.64 pu shown in fig 8 aWhile without tertiary as discussed in case (2) $3.14 \mathrm{pu}$ voltage observed.

2) Low side switching: switching with tertiary was modelled and open ended voltage obtained 2.50 pu voltage shown in fig $8 \mathrm{~b}$ while without tertiary it was $2.3 \mathrm{pu}$ discussed in case 5. In this particular case reactor at $50 \%$ (1050 Mvar) is coupled with tertiary but no significant reduction in voltage was obtained.

Synchronous machine and 2.27 pu voltage is obtained shown in fig 6 .

\section{Series Compensation}

In order to increase transmission capacity, each line is series compensated by capacitors representing $40 \%$ of line reactance and similar operation like case 1 and case 2 is performed with this model and no significant change in wave shape or magnitude is observed shown in fig $7 \mathrm{a} \& 7 \mathrm{~b}$. 


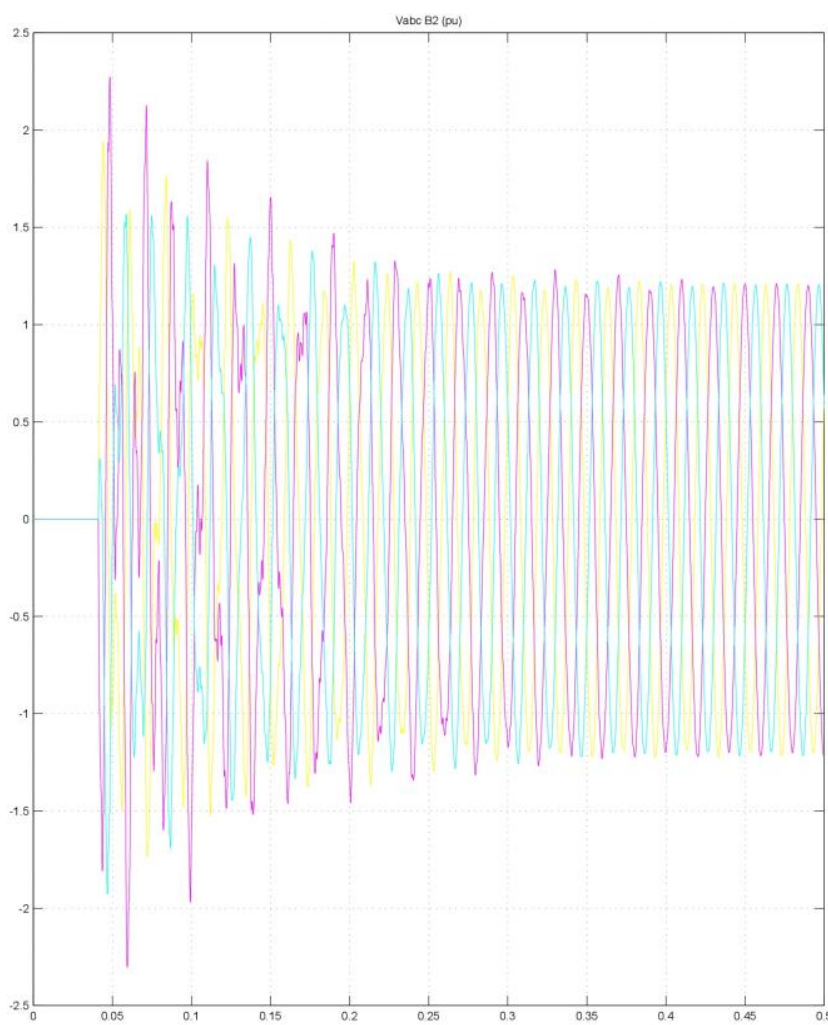

Figure 6: $(0.5 \mathrm{pu} / \mathrm{div}$ vertical axis, $0.05 \mathrm{sec} / \mathrm{div}$ horizontal

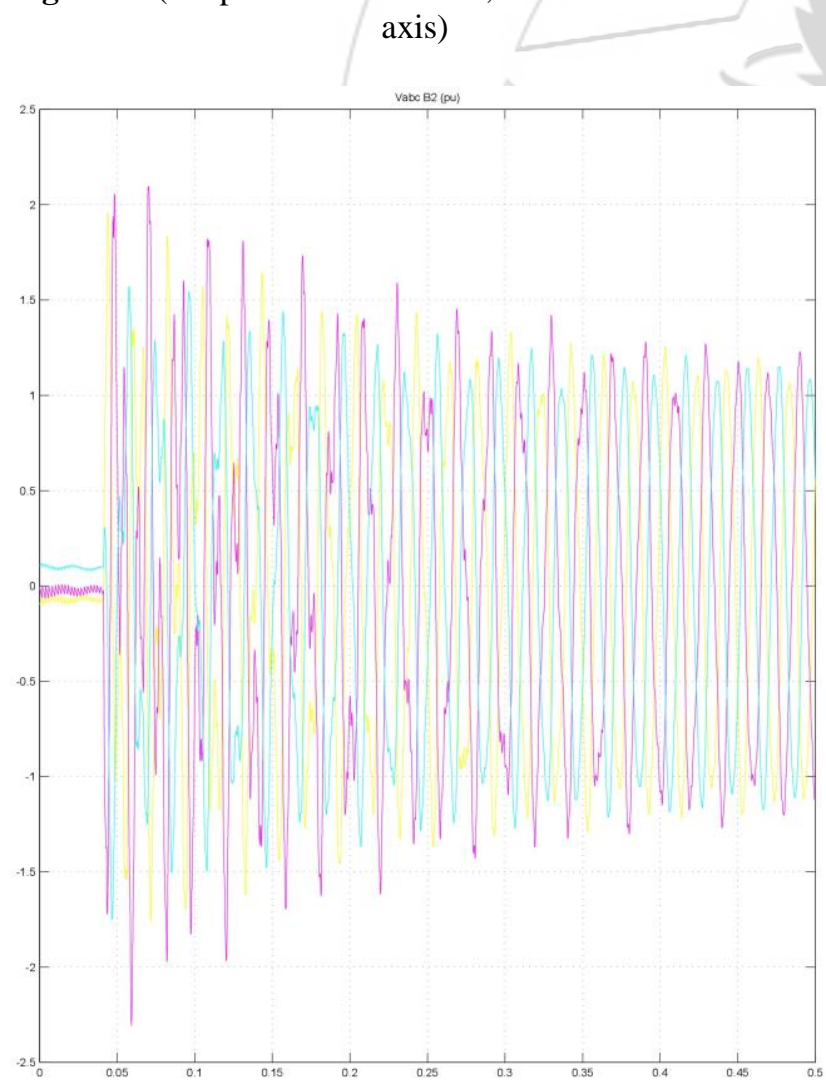

Figure 7a: $(0.5 \mathrm{pu} / \mathrm{div}$ vertical axis, $0.05 \mathrm{sec} / \mathrm{div}$ horizontal axis)

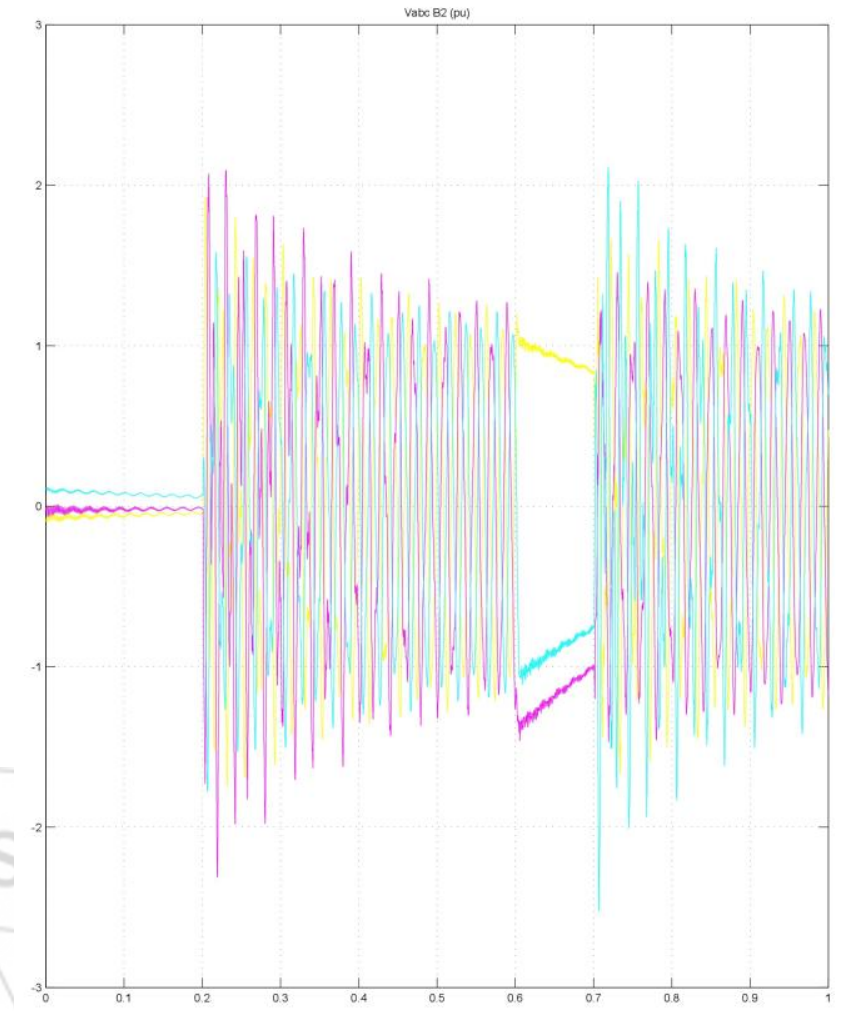

Figure 7b: (1 pu/div vertical axis, $0.1 \mathrm{sec} / \mathrm{div}$ horizontal axis)

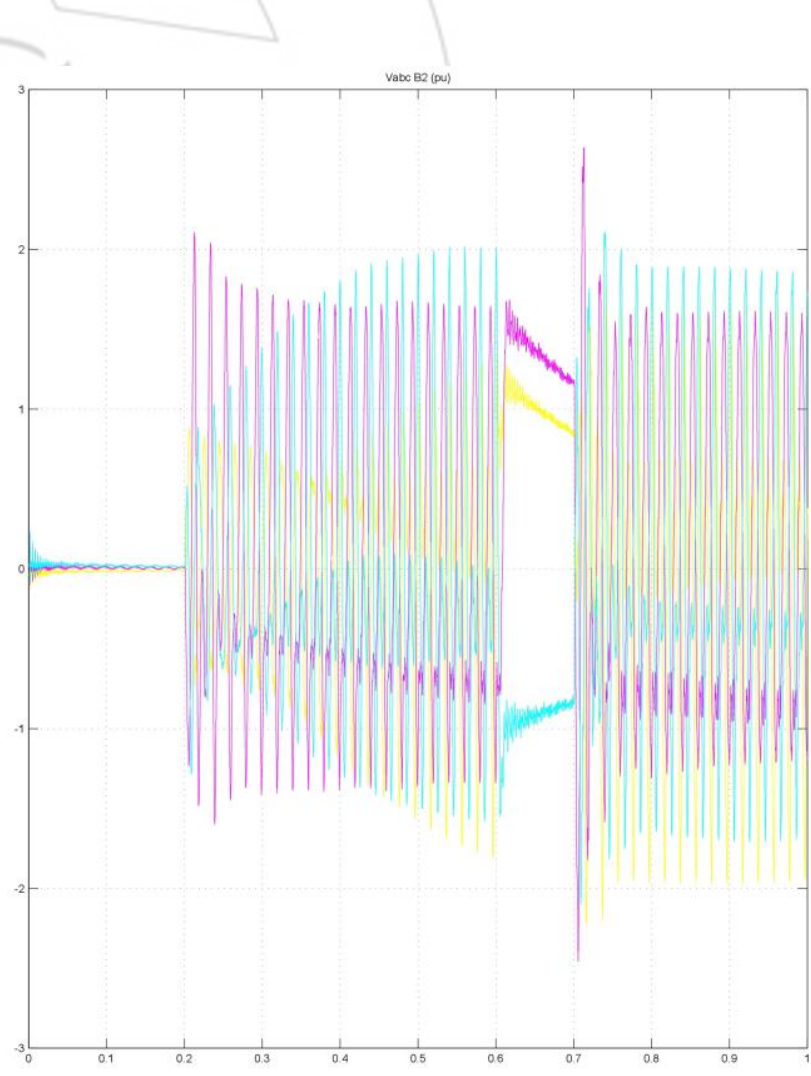

Figure 8a: (1 pu/div vertical axis, $0.1 \mathrm{sec} / \mathrm{div}$ horizontal axis) 


\section{International Journal of Science and Research (IJSR) \\ ISSN (Online): 2319-7064}

Index Copernicus Value (2013): 6.14 | Impact Factor (2015): 6.391

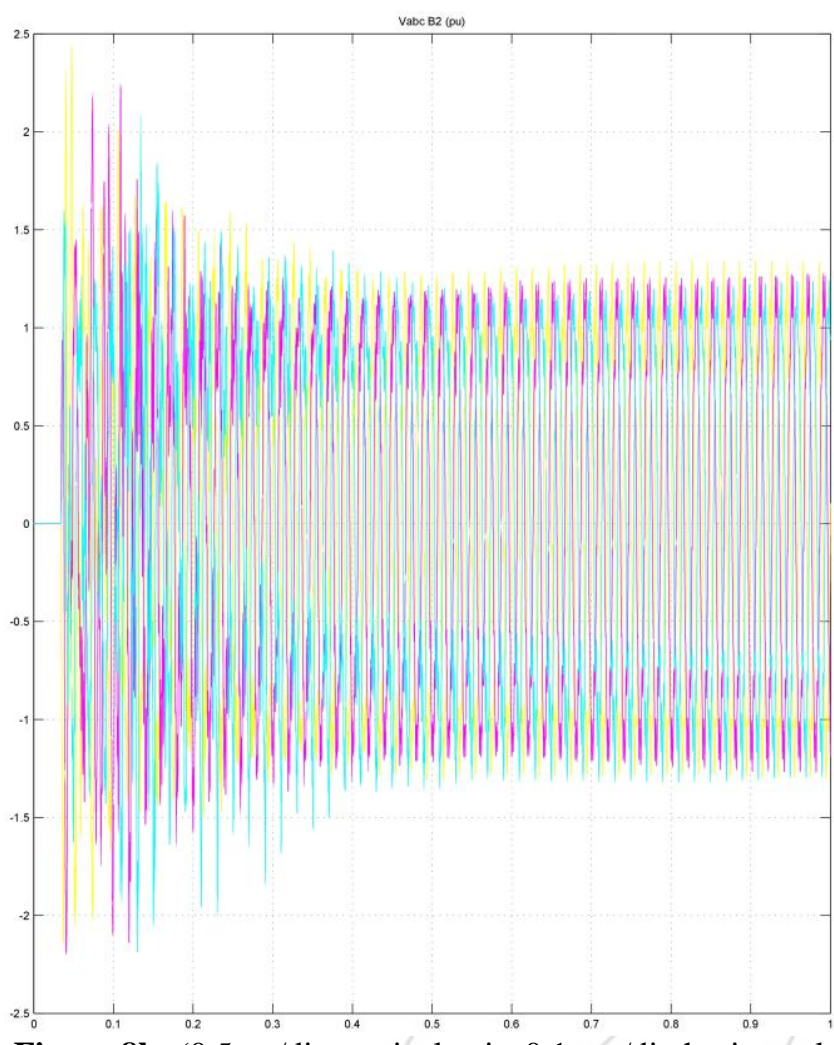

[4] A.R.Hileman et al.," Estimating the switching surge performance of Transmission lines," IEEE Trans. On PAS, VOL.89, NO. 5, pp. 1445-1469, September/October 1970.

[5] CIGRE Working Group 13-02, "switching overvoltages in EHV and UHV systems with special Reference to closing and reclosing Transmission lines," Electra, no. 30, pp. 70-122, October 1973.

[6] AIEE Committtee Report, "switching surges, I- phase to ground voltages," Trans. AIEE (power apparatus and systems), vol 81, pp. 312-320, August 1962.

Figure 8b: $(0.5 \mathrm{pu} / \mathrm{div}$ vertical axis, $0.1 \mathrm{sec} / \mathrm{div}$ horizontal axis)

\section{Conclusion}

1) Reenergization of line with high side breaker produces highest switching surges as discussed in case 2 which is also called sudden reclosing.

2) In our modelling we have taken source with $2100 \mathrm{MVA}$, $13.8 \mathrm{kv}$ and transformer with $13.8 / 735 \mathrm{kv}$ and line length $300 \mathrm{~km}$ but with increase in these ratings increase the surge magnitude.

3) Low side switching produce lower voltage at open end than high side switching. There is some effect of tertiary is also observed.

4) Deenergization of line after fault give high overvoltage of sound phases.

5) In single phase reclosing due to mutual coupling from other phases C.B reenergizes the faulted phase from stored charges.

6) Presence of series compensation upto 40-50\% line reactance does not affect surge magnitude and wave shape.

\section{References}

[1] Rakosh das begamudre,extra high voltage A.C Transmission engineering, $2^{\text {nd }}$ edition 1990 , wiley eastern limited.

[2] J.SABATH, H.M. SMITH, R.C. JOHNSON, "Analog computer study of switching surge transients for $500 \mathrm{kv}$ system," IEEE Trans. On power Apparatus and systems, vol. PAS-85, NO 1, January, 1966.

[3] D.E. Hedman, I.B.Johnson, C. H. Titus and D.D. Wilson, "switching of extra high voltage circuits, II- Surge reduction with circuit breakers resistors," IEEE Trans. On power Apparatus and systems, vol. 83, pp. 1196-1205, December 1964. 